\title{
Naturally occurring genotypic drug-resistant mutations of HBV in Huzhou, China: a single-center study
}

This article was published in the following Dove Press journal: Infection and Drug Resistance

\section{Fuchu Qian' \\ Weihua Zou ${ }^{2}$ \\ Jiqu Qin' \\ Dongli Li'}

'Huzhou Key Laboratory of Molecular Medicine, ${ }^{2}$ Department of Laboratory Medicine, Huzhou Central Hospital, Huzhou, China
Correspondence: Fuchu Qian Huzhou Key Laboratory of Molecular Medicine, Huzhou Central Hospital, 198 HongQi Road, Huzhou 313000, Zhejiang Province, China

Tel +86572 255580 I

Email qfc313009@I26.com
China is an area with highly endemic hepatitis B virus (HBV) infection, with an estimated 93 million HBV carriers, resulting in approximately 330,000 deaths annually. ${ }^{1}$ The predominant HBV genotypes in China are genotype B and C. Currently, nucleos(t)ide analogs are used for anti-HBV treatment. However, prolonged antiviral therapy may lead to drug resistance, which is associated with mutations in the reverse transcriptase region of the HBV genome. Several studies have shown that drug-resistant mutations existed in treatment-naïve patients with chronic hepatitis B (CHB). However, the prevalence rates of natural drug-resistant mutations varied in different reports. ${ }^{2,3}$ Furthermore, the prevalence and clinical profile of natural drug-resistant mutations in CHB patients are not quite clear. Thus, the purpose of this study was to investigate the prevalence and clinical feature of natural drug-resistant mutations among treatmentnaïve CHB patients in a tertiary hospital in Huzhou, eastern China.

In this study, we recruited $218 \mathrm{CHB}$ patients who had not received anti-HBV treatment in Huzhou Central Hospital. The diagnosis of CHB was done according to the Chinese consensus criteria. This study was approved by the ethics committee of Huzhou Central Hospital in accordance with the ethical guidelines of the Declaration of Helsinki. All patients provided written informed consent. Routine serological examination was performed by the technicians in Department of Laboratory Medicine. Serum HBV DNA levels were quantified using real-time polymerase chain reaction. The reverse transcriptase region amplification and sequencing was performed as described previously. ${ }^{4}$

Among 213 successfully sequenced sample from patients, natural drug-resistant mutations were detected in 6.1\% (13/213) patients, and these included rtM204I/V $(\mathrm{n}=8), \mathrm{rtL} 180 \mathrm{M}(\mathrm{n}=4), \mathrm{rtA181T} / \mathrm{V}(\mathrm{n}=4), \mathrm{rtL} 80 \mathrm{I} / \mathrm{V}(\mathrm{n}=4), \mathrm{rtV} 173 \mathrm{~L}(\mathrm{n}=2)$, and rtN236T $(\mathrm{n}=2)$. The clinical information of these patients is shown in Table 1. The prevalence rates of natural drug-resistant mutations in CHB patients were found to be varied in different areas of China (from $2.01 \%$ to $8.9 \%$ ). ${ }^{2,3}$ A meta-analysis revealed that the pooled incidence of natural resistance mutations in China is higher than those in other countries $(8.00 \%$ vs $1.88 \%) .{ }^{5}$ The incidence rate of natural resistance mutations in our study was not in agreement with the results of other studies. The discordance between previous studies and our results might be due to discrepancy of sample size and differences in study method, genotypic distribution, and study population. The actual prevalence of natural drug-resistant mutations in treatment-naïve patients may 
Table I Characteristics of patients with natural drug-resistant mutations

\begin{tabular}{|c|c|c|c|c|c|c|}
\hline Case No & Sex & Age & HBeAg status & $\begin{array}{l}\text { HBV DNA } \\
\text { (logIU/mL) }\end{array}$ & HBV genotype & Drug-resistant mutations \\
\hline I & M & 59 & - & 4.59 & B & AI8IT N236T \\
\hline 2 & $\mathrm{~F}$ & 45 & + & 6.67 & C & VI73L LI80M M204V \\
\hline 3 & M & 62 & + & 4.78 & C & VI73L \\
\hline 4 & M & 46 & + & 4.39 & C & Al8IV \\
\hline 5 & $M$ & 21 & + & 7.27 & B & LI80M M204V \\
\hline 6 & M & 55 & - & 4.85 & C & LI80M M204I \\
\hline 7 & M & 32 & + & 7.36 & C & VI73L M204I \\
\hline 8 & $\mathrm{~F}$ & 43 & - & 6.41 & C & AI8IT N236T \\
\hline 9 & $M$ & 39 & - & 3.55 & B & L80I M204I \\
\hline 10 & M & 36 & + & 6.65 & B & L80V M204I \\
\hline II & $\mathrm{F}$ & 45 & - & 7.47 & B & L80I M204I \\
\hline 12 & $\mathrm{~F}$ & 33 & + & 4.50 & C & L80I LI80M M204I \\
\hline 13 & $M$ & 30 & + & 8.69 & B & $\mathrm{A} I 81 \mathrm{~T}$ \\
\hline
\end{tabular}

Abbreviation: $\mathrm{HBV}$, hepatitis B virus.

Table 2 Clinical and virological characteristics of patients with and without drug-resistant mutations

\begin{tabular}{|c|c|c|c|}
\hline Characteristics & $\begin{array}{l}\text { Patients with } \\
\text { drug-resistant mutations } \\
(n=13)\end{array}$ & $\begin{array}{l}\text { Patients without } \\
\text { drug-resistant mutations } \\
(\mathrm{n}=\mathbf{2 0 0})\end{array}$ & $P$-value \\
\hline Gender (male/female) & $9 / 4$ & $|4| / 59$ & 0.570 \\
\hline Age (years) & $42.0 \pm 11.9$ & $36.2 \pm 12.6$ & 0.110 \\
\hline HBeAg status (+/-) & $8 / 5$ & $116 / 84$ & 0.802 \\
\hline HBV DNA (loglU/mL) & $5.93 \pm 1.57$ & $6.22 \pm 1.71$ & 0.560 \\
\hline HBV genotype(B/C) & $6 / 7$ & $121 / 76$ & 0.275 \\
\hline ALT (IU/L) & $125.1 \pm 235.2$ & $152.1 \pm 249.3$ & 0.705 \\
\hline AST (IU/L) & $100.9 \pm 190.8$ & $90.9 \pm 165.6$ & 0.834 \\
\hline ALP (IU/L) & $103.7 \pm 40.9$ & $96.9 \pm 39.7$ & 0.549 \\
\hline GGT (IU/L) & $79.6 \pm 129.4$ & $63.0 \pm 85.1$ & 0.511 \\
\hline
\end{tabular}

Abbreviations: ALP, alkaline phosphatase; ALT, alanine aminotransferase; AST, aspartate aminotransferase; GGT, gamma-glutamyl transpeptidase; HBV, hepatitis B virus.

be higher than our results show considering the low sensitivity of direct sequencing (mutation frequency $>20 \%$ ). Nonetheless, the current study provides a rationale for the further large-scale investigation on prevalence of natural resistance mutations by the next-generation sequencing technologies.

At present, we compared the clinical and virological characteristics between the patients with and without natural drug-resistant mutations (Table 2). No significant correlation was found between natural drug-resistant mutations and gender, age, HBeAg status, HBV DNA levels, proportion of genotype $\mathrm{C}$, and liver function biochemical markers, including alanine aminotrasferase (ALT), aspartate aminotransferase (AST), alkaline phosphatase (ALP), and $\gamma$-glutamyl transpeptidase (GGT) (all $P>0.05$ ). To date, the clinical significance of natural drug-resistant mutations is unclear. Recently, one study showed that no significant correlation was found between natural drug-resistant mutations and clinical features, including gender, age, genotype, $\mathrm{HBeAg}$ status, HBV DNA loads or ALT and AST values. ${ }^{6}$ On the contrary, another study reported that natural resistance mutations may be correlated with HBV DNA levels and genotype. ${ }^{7}$ Hence, large-scale investigations on natural drug-resistant mutations are needed to further clarify the clinical significance of natural resistance mutations in CHB patients.

In summary, the present study shows that the primary drug-resistance mutations (rtM204V/I, rtA181T/V, and rtN236T) and secondary drug-resistance mutations (rtL80V/I, rtV173L, and rtL180M) existed in treatmentnaïve CHB patients in Huzhou, eastern China. Considering that pre-existing drug-resistant mutations may affect the efficiency of antiviral therapy, it is necessary to monitor the nucleos(t)ide analog resistance mutations before antiviral therapy.

\section{Acknowledgment}

This work was supported by grants from the Foundation Projects for Science and Technology of Huzhou City (No. 2014GY12, No. 2017GY30). 


\section{Disclosure}

The authors report no conflicts of interest in this work.

\section{References}

1. Guo Y, Xu J, Li J, et al. An epidemiological serosurvey of hepatitis B virus shows evidence of declining prevalence due to hepatitis B vaccination in central China. Int J Infect Dis. 2015;40:75-80.

2. Li X, Liu Y, Zhao P, et al. Investigation into drug-resistant mutations of HBV from 845 nucleoside/nucleotide analogue-naive Chinese patients with chronic HBV infection. Antivir Ther. 2015;20:141-147.

3. Zhao Y, Wu J, Sun L, et al. Prevalence of mutations in HBV DNA polymerase gene associated with nucleos $(\mathrm{t})$ ide resistance in treatment-naive patients with Chronic Hepatitis B in Central China. Braz J Infect Dis. 2016;20:173-178.
4. Qian F, Qin J, Li D, et al. Monitoring of genotypic resistance profile in chronic hepatitis B patients receiving nucleos(t)ide analogues in Huzhou, China. J Infect Dev Ctries. 2016;10:996-1002.

5. Zhang Q, Liao Y, Cai B, et al. Incidence of natural resistance mutations in naïve chronic hepatitis B patients: a systematic review and meta-analysis. J Gastroenterol Hepatol. 2015;30:252-261.

6. $\mathrm{Xu} \mathrm{J}, \mathrm{Wu} \mathrm{B}$, Wang JH, et al. Pre-existing mutations in reverse transcriptase of hepatitis B virus in treatment-naive Chinese patients with chronic hepatitis B. PLoS One. 2015;10:e117429.

7. Mirandola S, Sebastiani G, Rossi C, et al. Genotype-specific mutations in the polymerase gene of hepatitis B virus potentially associated with resistance to oral antiviral therapy. Antiviral Res. 2012;96: $422-429$.
Infection and Drug Resistance

\section{Publish your work in this journal}

Infection and Drug Resistance is an international, peer-reviewed openaccess journal that focuses on the optimal treatment of infection (bacterial, fungal and viral) and the development and institution of preventive strategies to minimize the development and spread of resistance. The journal is specifically concerned with the epidemiology of antibiotic

\section{Dovepress}

resistance and the mechanisms of resistance development and diffusion in both hospitals and the community. The manuscript management system is completely online and includes a very quick and fair peerreview system, which is all easy to use. Visit http://www.dovepress.com/ testimonials.php to read real quotes from published authors.

Submit your manuscript here: https://www.dovepress.com/infection-and-drug-resistance-journal 